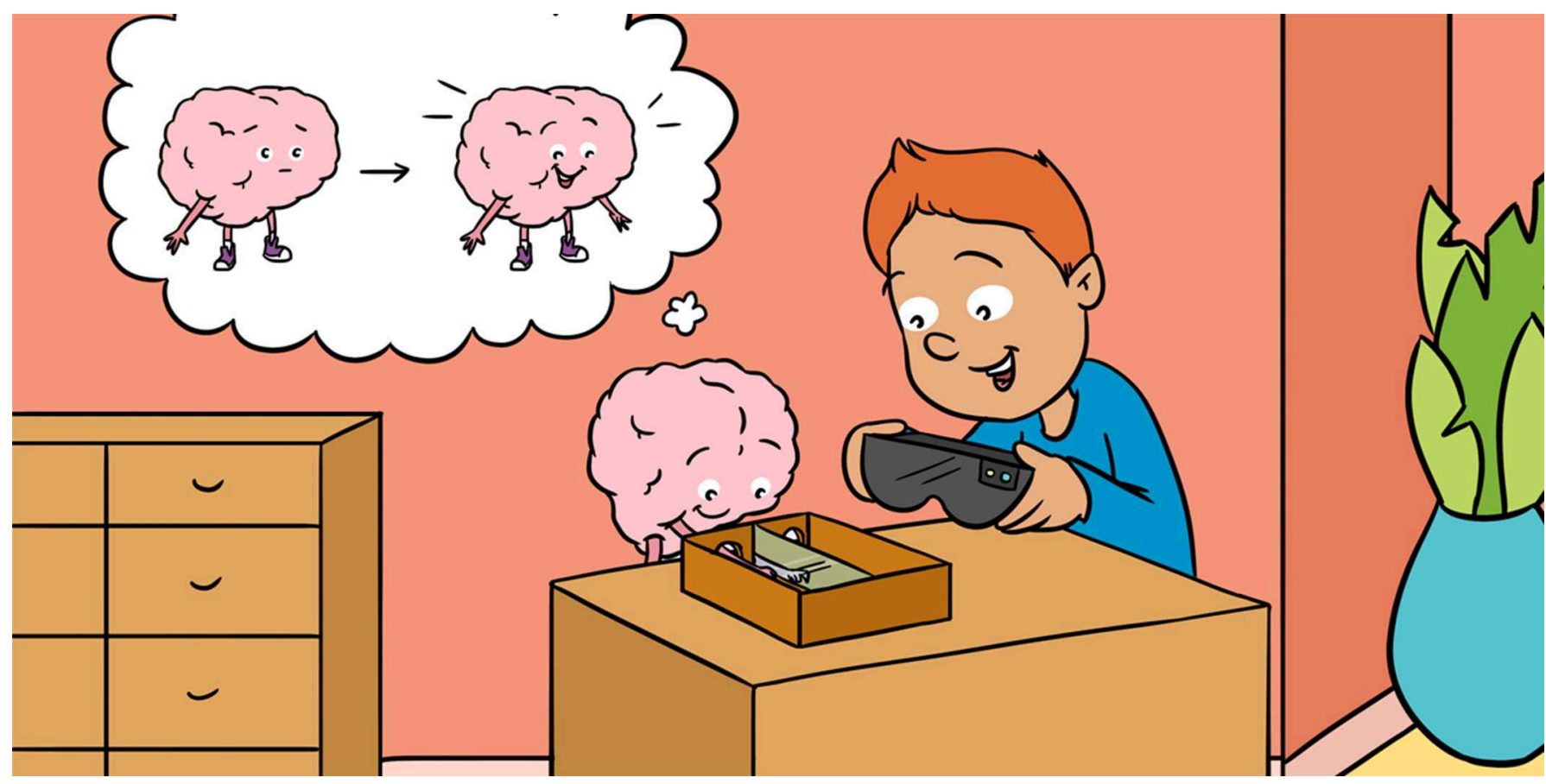

\title{
FOOLING THE BRAIN, FOOLING THE PAIN: THE ROLE OF MIRROR THERAPY AND MODERN USES IN VIRTUAL REALITY
}

\section{Charles Faure *, Annabelle Limballe and Hugo A. Kerhervé}

Univ Rennes, INRIA, M2S-EA 7470, Rennes, France

YOUNG REVIEWERS:

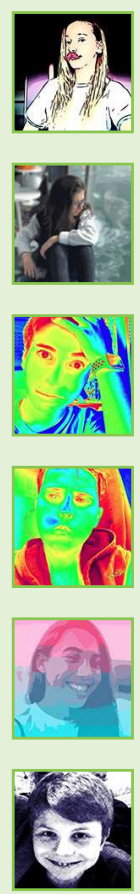

ANNA

AGE: 13

CATERINA

AGE: 14

FEDERICO

AGE: 14

FRANCESCO

AGE: 14

SOFIA

AGE: 14

TOMMASO

AGE: 14
The brain is the control center of the body, and has to process information coming from all five of the senses. One of the senses, vision, is often stronger than the others. Mirror therapy is a type of therapy that uses vision to treat the pain that people with amputated limbs sometimes feel in their missing limbs. Mirror therapy does this by tricking the brain: it gives the illusion that the missing limb is moving, as the person looks at the real, remaining limb in a mirror. This way, the brain ignores the fact that it receives no signal of movement from the amputated limb itself. Although very promising, mirror therapy has some limitations, and scientists are working to overcome these limitations so that mirror therapy can be used to address more complex movements or different kinds of pain. Virtual reality is a promising tool offering interactive, realistic, and modifiable environments that are able to trick the brain in more complex ways. 
Figure 1

Example of mirror box. This mirror box creates the illusion that the patient has two intact arms and that both arms are moving. The intact side is reflected in the mirror partition. A patient looking at the mirror sees the reflection of the intact limb and feels like the amputated limb is still present and moving. Image from BBC News archives.

\section{PHANTOM LIMB}

A syndrome in which patients experience the sensation that their amputated limb is still present. These patients can also feel pain or cramping in the missing limb.

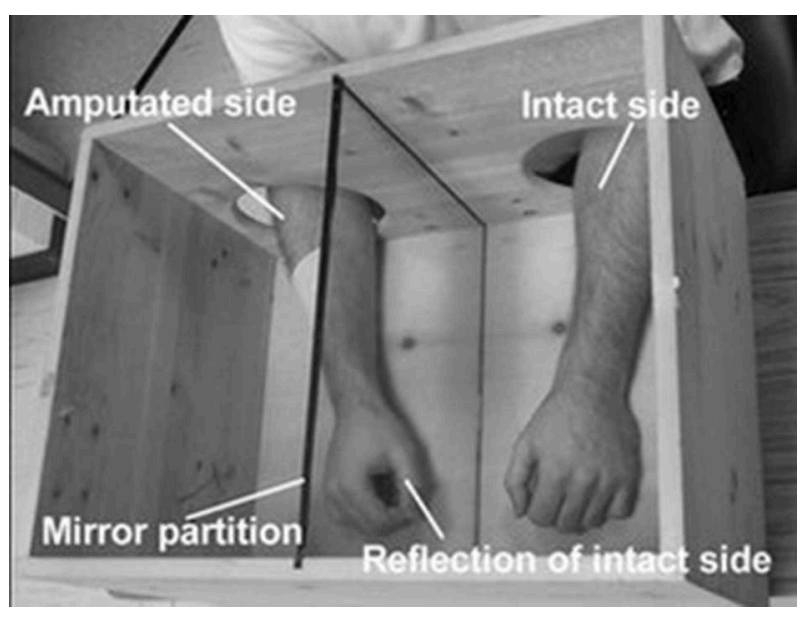

Figure 1

\section{WHY DO WE NEED TO FOOL THE BRAIN?}

Along with taste, smell, sound, and touch, vision is one of the five senses that enable us to gather information from the world that surrounds us. But vision can also be used as therapy to transmit information to the brain: 25 years ago, scientists in California (USA) led by Professor Ramachandran [1, 2] used vision to treat a well-known problem affecting people who had lost a limb (hand, leg, etc.). These amputees sometimes experienced unpleasant sensations of tickling, spasms, or even pain in that amputated limb, even though the limb was not physically there anymore. The scientists proposed that this "phantom limb" phenomenon was due to a miscommunication problem in the brain. Neurons (nerve cells) that had previously commanded muscles in the phantom (amputated) limb still exist in the brain, and can still send out signals, such as a request to move the limb. When these signals are sent, the brain expects signals in return, like the feelings of movement or touch, to indicate that the command was carried out. However, because the limb does not exist anymore, the brain signals never reach their destination (the muscles), and the limb cannot send sensory information back to the brain. This miscommunication creates a conflict that the scientists call negative feedback. To bypass this negative feedback, the scientists devised a plan to trick the brain of people with an amputated hand/arm into perceiving sensations, simply by looking at the other (real) hand/arm. In the original experiment, people placed both their amputated (phantom) and intact limbs in a box with a mirror on one side (see Figure 1). The amputees were instructed to move their existing fingers while looking in the mirror on the side of the phantom limb. With just 15 min of practice per day for 3 weeks, people were able to "feel" movement in the phantom limb, and more than half of the amputees were relieved of their phantom pain. In this study, the mirror therapy created an illusion of movement that broke the negative feedback loop. How is this possible? Can new technologies help us design new treatments based on these observations? 
MIRROR NEURONS

Neurons (nerve cells) that are activated both when someone performs an action and observes someone else performing the same action.

\section{NEUROPLASTICITY}

The brain's ability to reorganize its structure throughout a person's life.

\section{HOW DOES MIRROR THERAPY WORK?}

To better understand how this phenomenon works, researchers focused on two concepts: mirror neurons and neuroplasticity. Mirror neurons are neurons in the brain that are activated when you perform a task but are also activated when you look at someone else performing this task. However, these mirror neurons are only activated if you watch an action that you can perform yourself. For example, mirror neurons are not activated if you look at a bird flying. What is more surprising is that mirror neurons are also activated when a person is imagining an action but not performing it! This is also why you can sometimes feel what other people feel: if you see someone get his fingers caught in a door, you will probably "feel" that person's pain, and wince.

The brain is not a rigid network of neurons set in a given arrangement for life, like an old electrical board. The brain is constantly trying to find better ways to deliver and deal with information by creating or removing connections between neurons. This phenomenon of neural changes is called neuroplasticity. When babies are discovering the world around them with their five senses, their brains undergo intense development and remodeling. Later, when children learn to ride a bike, catch a ball, or play a musical instrument, more remodeling occurs, allowing the child to perform complicated actions without actually thinking about each and every step involved. When catching a ball that is flying toward you, you do not consciously think of using specific muscles at specific times, you just catch the ball, because your brain already knows which muscles must be activated and when. Neuroplasticity continues to take place during a person's entire life and can have lasting effects depending on your experience in a given activity: this is why, for example, the more you train in mental calculation, the more competent and fast you become.

If a specific area of the brain is damaged (from a stroke, disease, or trauma from an accident), that brain area can no longer send specific commands to the body. However, because neuroplasticity allows the brain to modify its organization, some people with brain damage can still recover some of their movements, thanks to the creation of new connections between neurons. These new connections offer new ways to send information, the same way a new bridge allows people to cross a river when the old bridge has collapsed. Overall, being young is a strong advantage in recovering movement after a brain injury, because neuroplasticity is at its peak when the brain is still developing. The younger you are, the better you can recover.

Now that you have learned a little about neuroplasticity, you can better understand how mirror therapy works to reduce unpleasant phantom limb sensations: the visual system tells the mirror neurons that the phantom limb is moving (even though it really is not). 
Figure 2

Exaggeration of head movement using virtual reality. When the participant was asked to move his head, the virtual head movement he saw through the VR viewer was exaggerated in the virtual world-it showed him moving his head more than he actually did. Even though he only rotated his head to the dashed line, he thought he rotated his head to the solid line. The VR world can fool the brain into feeling more movement than actually occurs. Image from Harvie et al. [3].

\section{VIRTUAL REALITY}

An artificial environment, created with a computer and software that presents users with a situation they can interact with (see, hear, touch, grab, etc.). The graphics can be so convincing that participants accept the environment real.

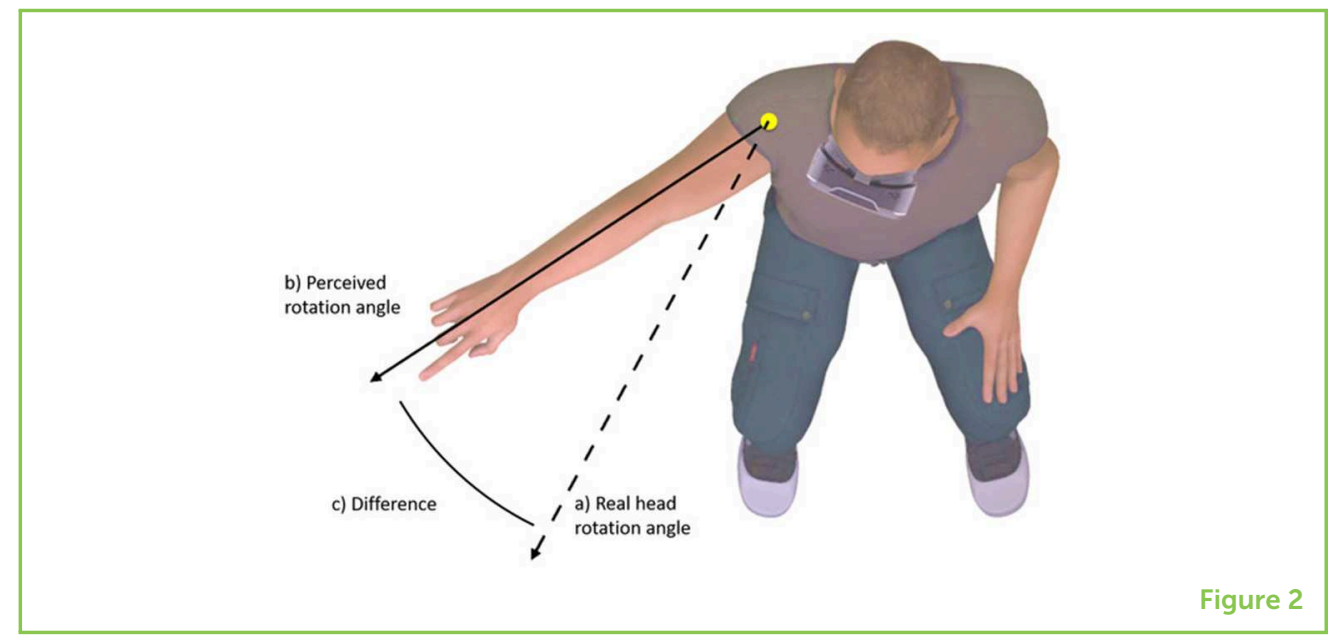

With training and a little patience, helping the brain to "see" and "feel" the amputated limb move can change the way the brain deals with signals, by eliminating the old negative feedback ("the phantom limb is not moving") and establishing new connections to "feel" the limb again.

\section{CAN WE MAKE A BETTER MIRROR?}

Mirror therapy has been tested and has shown promising results for the treatment of other health problems, including chronic pain, re-education of the brain after stroke, and even arthritis. However, the use of mirror therapy is still very limited and much remains to be done to improve this therapy and its use.

While traditional mirror therapy only allows for small movements and cannot provide a truly realistic experience to fool the brain and give it the illusion of movement, the new technology of virtual reality (VR) offers just that. VR gives a person the illusion of movement by dropping them in a three-dimensional environment and giving them an avatar, or the appearance of a body. With VR, people can interact in an environment generated by a computer, as if they were in a video game! Unlike traditional mirror therapy, VR offers the illusion of movement for body parts that do not come in pairs, like the head, for example. A team of researchers recently asked people immersed in VR to turn their heads to the side, but manipulated what they were seeing, making them think they moved their heads more than they really did [3]. When the people were then asked to say how much their heads really moved, they always overestimated the movement. As illustrated in Figure 2, their perceived movement was influenced by incorrect visual information that overpowered the actual feeling of movement itself-they were tricked by the VR experience!

Another problem with traditional mirror therapy is that it cannot always be used to help people with amputated legs to walk again, or to reduce 


\section{SERIOUS GAME}

A game that has been designed for a purpose other than pure entertainment: pedagogy, education, reeducation, etc. their pain. AVR version of mirror therapy was created to help with this [4]. A man with a prosthetic leg was shown an avatar of himself in which his missing leg looked like a normal leg. For the participant, it was as if he was actually walking with two real legs. Over time, the slight asymmetry in his walk was progressively reduced and his limp almost disappeared.

\section{CONCLUSION}

Traditional mirror box therapy has proven to be a very simple and interesting method to help with the phantom limb phenomenon. However, the use of mirror therapy is limited to simple movements involving a single arm or leg. Because of this limitation, we have turned to new techniques and technologies. VR has shown promise in this domain, and has become more than simply a tool for gaming and entertainment. VR has many advantages, including the ability to create realistic, interactive, and modifiable environments to distract the brain from the other senses. Furthermore, VR allows scientists to incorporate other senses into the experience, like hearing or touch. VR could be used, for example, to design serious games for the treatment of patients suffering from phantom limb syndrome or other limitations of movement. In conclusion, tricking the brain through VR is a promising new technology for helping the brain adapt to the challenges posed by amputations or other injuries affecting movements of the body.

\section{REFERENCES}

1. Ramachandran, V. S., Rogers-Ramachandran, D., and Cobb, S. 1995. Touching the phantom limb. Nature 377:489-90. doi: 10.1038/377489a0

2. Ramachandran, V. S., and Rogers-Ramachandran, D. 1996. Synaesthesia in phantom limbs induced with mirrors. Proc. Biol. Sci. 263:377-86. doi: 10.1098/rspb.1996.0058

3. Harvie, D. S., Smith, R. T., Hunter, E. V., Davis, M. G., Sterling, M., and Moseley, G. L. 2017. Using visuo-kinetic virtual reality to induce illusory spinal movement: the moovi illusion. PeerJ 5:e3023. doi: 10.7717/peerj.3023

4. Barton, G. J., De Asha, A. R., van Loon, E. C., Geijtenbeek, T., and Robinson, M. A. 2014. Manipulation of visual biofeedback during gait with a time delayed adaptive virtual mirror box. J. Neuroeng. Rehabil. 11:101. doi: 10.1186/1743-0003-11-101

SUBMITTED: 13 November 2018; ACCEPTED: 18 June 2019; PUBLISHED ONLINE: 03 July 2019.

EDITED BY: Marcel Ruiz-Mejias, Universidad Pompeu Fabra, Spain

CITATION: Faure C, Limballe A and Kerhervé HA (2019) Fooling the Brain, Fooling the Pain: The Role of Mirror Therapy and Modern Uses in Virtual Reality. Front. Young Minds 7:91. doi: 10.3389/frym.2019.00091 


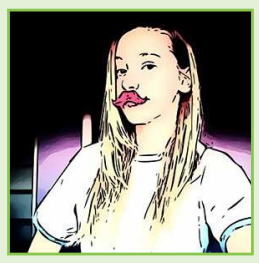

CONFLICT OF INTEREST STATEMENT: The authors declare that the research was conducted in the absence of any commercial or financial relationships that could be construed as a potential conflict of interest.

COPYRIGHT @ 2019 Faure, Limballe and Kerhervé. This is an open-access article distributed under the terms of the Creative Commons Attribution License (CC BY). The use, distribution or reproduction in other forums is permitted, provided the original author(s) and the copyright owner(s) are credited and that the original publication in this journal is cited, in accordance with accepted academic practice. No use, distribution or reproduction is permitted which does not comply with these terms.

\section{YOUNG REVIEWERS}

\section{ANNA, AGE: 13}

$\mathrm{Hi} \mathrm{I} \mathrm{am} \mathrm{Anna,} \mathrm{I} \mathrm{am} 13$ years old and I am short, really short. Nevertheless, I am full of energy and creativity! I love drawing; in fact I can draw everything, from hamburgers to vampires: for me drawing is a real passion! I am studying at Istituto Leopardi.
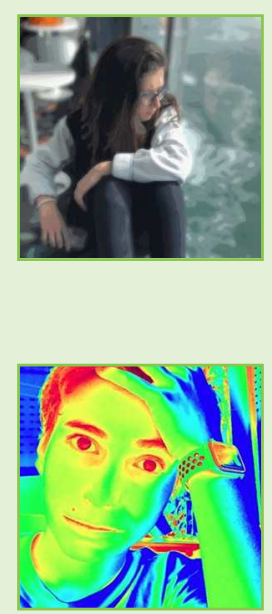

\section{CATERINA, AGE: 14}

$\mathrm{Hi}$, I am Caterina and I am 14 years old. The swimming pool is my second home: In fact I love swimming, in particular synchronized swimming. I like learning new things and my favorite subjects are English and Italian. I study at Istituto Leopardi, and next year I will start the Liceo Classico.

\section{FEDERICO, AGE: 14}

$\mathrm{Hi}$, I am Federico and I am 14. I am studying in Istituto Leopardi and this is my last year there. I love playing football and videogames. I have a lot of friends and I spend a lot of time with them. My favorite football team is Inter FC, and I usually go to the stadium.

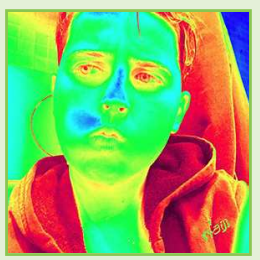

\section{FRANCESCO, AGE: 14}

Hi my name is Francesco, My favorite sport is tennis, but I also love football, and my favorite club is AC Milan. I am studying at the Istituto Leopardi, an excellent school. When I will finish the secondary school I will go to Liceo Classico. My favorite subjects are Maths, Italian, and English. I am sure that my life will be fantastic!

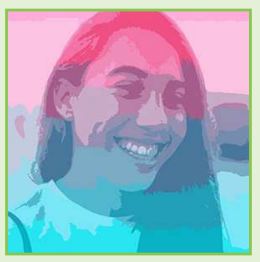

\section{SOFIA, AGE: 14}

Hi I am Sofia, I am 14 years old and I study at Istituto Leopardi. My favorite subject is English because I love to study languages. I play tennis and beach volley. 

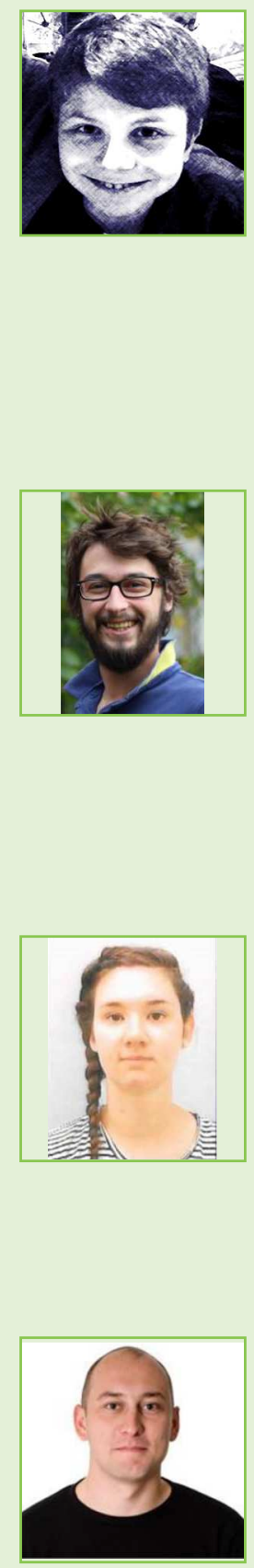

\section{TOMMASO, AGE: 14}

Hi I am Tommaso, and I study at Istituto Leopardi. I like history quite enough, but I also like science and using new technologies. I love music, in particular the instrumental one, and I play the piano. I really love music!!!!!!!!!! And I like creating it. I also love writing and making some small stop-motion movies with LEGO. Year by year I try to improve myself in everything I do, together with the school and my parents, and with a brother who helps me a lot in everything.

\section{AUTHORS}

\section{CHARLES FAURE}

I am a Ph.D. student in virtual reality (VR) and its application to team sport contexts, in the M2S-lab in Rennes (France). More specifically, I am interested in the way players interact in order to make the right decisions at the right times. Through virtual reality standardized situations, I try to understand how movement and decisions emerge from interactions between players, and how these can be optimized to be more efficient. I am also interested in medical applications of VR technology. During my spare time, I enjoy playing sports and improving my general knowledge! *charles.faure@ens-rennes.fr

\section{ANNABELLE LIMBALLE}

My name is Annabelle Limballe and I am 24. I am currently completing my Master's Degree in Sport Sciences. More than only sports, I am interested in motor control, which is the understanding of how the body works and how the brain controls movements. Since I was a kid, I have been practicing various team sports, such as soccer and basketball. I am now involved in studies and research projects based on my initial interest in sports, and my pleasure in practicing sports became a pleasure to study them!

\section{HUGO A. KERHERVÉ}

My goal as a Sport Science Teacher and Researcher is to think of ways to make people move and be active regardless of their age, experience, or health. I study human movement using different methods, such as the measure of energy expenditure, motion capture, and muscle activity. These measures are then used to evaluate the effect of a treatment, of training, or the use of sports equipment, and to help decide whether these things are helping people or not. 